\title{
Female segregation patterns of the putative Y-chromosome-specific microsatellite markers INRA124 and INRA126 do not support their use for cattle population studies
}

\author{
L. Pérez-Pardal*, L. J. Royo*, I. Álvarez* , F. A. Ponce de León ${ }^{\dagger}$, I. Fernández* , R. Casais ${ }^{\ddagger}$ and \\ F. Goyache* \\ *SERIDA-Somió, C/ Camino de los Claveles 604, E-33203 Gijón (Asturias), Spain. 'Department of Animal Science, University of Minnesota, \\ 480 Haecker Hall, 1364 Eckles Avenue, St Paul, MN 55108, USA. ${ }^{\ddagger}$ SERIDA-Jove, Jove del Medio, E-33299, Gijón (Asturias), Spain
}

\section{Summary}

\begin{abstract}
Here we tested the segregation and paternal compatibility of markers INRA124 and INRA126 on female DNA in 10 different cattle families, in order to clarify the usefulness of these microsatellites for the study of male-mediated population processes in cattle. Their performance was compared with that of four microsatellites located in the PAR-BTAY (UMN0108, UMN0803, UMN0929 and UMN0905) and another one male-specific microsatellite (INRA189). INRA124 and INRA126 amplified the same sized fragment in both sexes. Same size alleles were sequenced and the high homology found allowed us to rule out non-specific female amplification. INRA124 showed full parental compatibility, whilst the locus INRA126 showed 55\% parental incompatibility. Based on these observations, it is recommended that markers INRA124 and INRA126 should not be used in studies to characterize male-mediated genetic events in cattle.
\end{abstract}

Keywords cattle, INRA124, INRA126, phylogeny, Y-chromosome, Y-specific markers.
Assessment of neutral genetic variability on the Y-chromosome in livestock is of high interest to ascertain male genetic legacies throughout the history of a species (MacHugh \& Bradley 2001). The number of studies on bovine Y-chromosome (BTAY) polymorphisms has quickly increased (Vaiman et al. 1994; Hanotte et al. 1997; Liu et al. 2003). Such studies have focused on the assessment of male-mediated migration patterns and admixture between Bos taurus and Bos indicus (Hanotte et al. 2000; Li et al. 2007). The number of polymorphic-specific markers identified on BTAY is limited (Vaiman et al. 1994; Kappes et al. 1997; Liu et al. 2003) and most population genetic studies in cattle have included INRA124 and INRA126 (Edwards et al. 2000, 2007; Giovambattista et al. 2000; Hanotte et al. 2000; Li et al. 2007), which were identified and reported to be male-specific by Vaiman et al. (1994). Indeed, the chromosomal location of the X- and Y-specific regions on both BTAX and BTAY has remained controversial (Liu et al. 2003).

This research aims to clarify the usefulness of the markers INRA124 and INRA126 for the study of male-mediated

Address for correspondence

F. Goyache, SERIDA-Somió, C/ Camino de los Claveles 604, E-33203 Gijón (Asturias), Spain.

E-mail: fgoyache@serida.org

Accepted for publication 18 January 2009 population processes in cattle. This is justified by the uncertainty of their physical location on BTAY and the lack of systematic tests for the amplification of these markers on female DNA. Here, we test the amplification of these markers on female DNA and their segregation and paternal compatibility (markers clonally inherited from father to son) on 10 different cattle families (see Pedigrees in Fig. 1). Their performance is compared with that of five BTAY microsatellites, four located in the pseudo-autosomal region (PAR) of BTAY (UMNO108, UMNO803, UMN0929 and UMNO905; Liu \& Ponce de León 2007) and another male-specific microsatellite (INRA189; Kappes et al. 1997) (Table 1). This will contribute to the ascertainment of the ability of these markers to reflect only the evolutionary histories of male lineages.

As expected, INRA189 amplified only from males (Table 2). The four microsatellites located in the PAR-BTAY (UMN0108, UMN0803, UMN0905 and UMNO929) amplified alleles of the same size range both on male and female DNA, showing full parental compatibility except for UMNO108 and UMNO905 (see Table 2, Appendix S1). INRA124 amplified in both sexes with alleles of the same sizes and showed full parental compatibility. INRA126 showed a more erratic behaviour. It amplified in both sexes with alleles of the same sizes, but the frequency of parental incompatibility was $55 \%$ (see Table 2). Alleles of the same 
Figure 1 Description of analysed pedigrees of the Asturiana de los Valles beef cattle. Sires are identified using numbers from 1 to 10 whilst dams are identified with letters from $A$ to S. Offspring are identified combining the corresponding number and letter with exception of two twin females calves that are identified by adding the symbols $\alpha$ and $\beta$. Paternity was confirmed in all cases using the 11 genomic StockMarks Kit for Cattle Bovine Genotyping (Applied Biosystems Inc.).

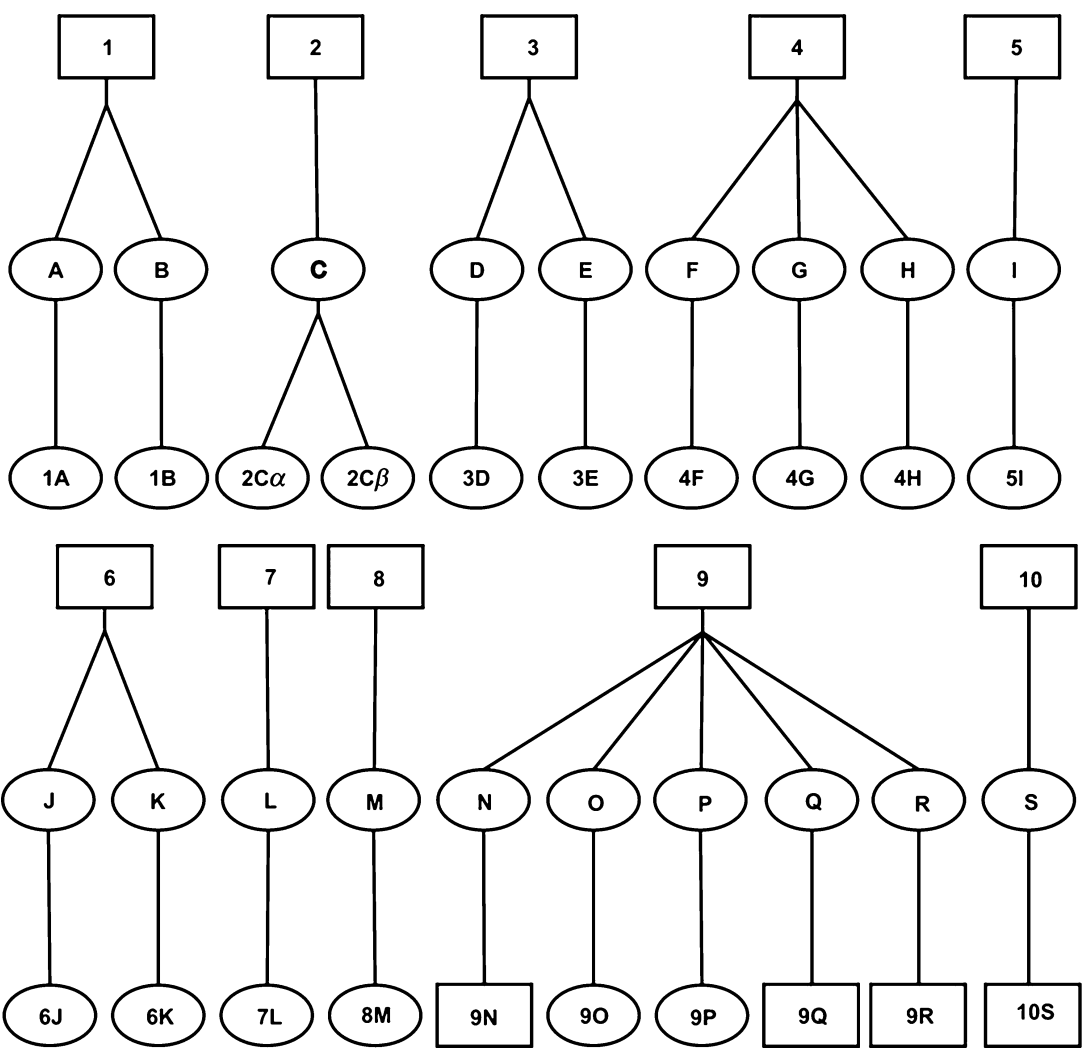

Table 1 Description of the microsatellite markers tested.

\begin{tabular}{|c|c|c|c|c|c|}
\hline Marker & Primer sequences $\left[5^{\prime}-3^{\prime}\right]$ & No. alleles ${ }^{1}$ & Size range ${ }^{1}$ & Location $^{2}$ & Reference \\
\hline \multirow[t]{2}{*}{ UMN0108 } & GATCСАТССАСАТTGСТССА-Uр & 5 & 190-208 & PAR & Liu et al. (2003) \\
\hline & CCAAGCGTCCATCAATTTAC-dn & & & & \\
\hline \multirow[t]{2}{*}{ UMN0803 } & GATCCACATCССССТСАС-up & 2 & $260-279$ & PAR & \\
\hline & СTGСTTCTCTTGTCCGCTAA-dn & & & & \\
\hline \multirow[t]{2}{*}{ UMN0929 } & ACCAGCTGATACACAAGTGC-up & 8 & 174-196 & PAR & \\
\hline & GGTCAGAGAATGAAACAGAG-dn & & & & \\
\hline \multirow[t]{2}{*}{ UMN0905 } & ATCAACCGTGGTAGCTCTAA-up & 4 & $158-164$ & PAR & \\
\hline & CTAGAATGTAAACCAGCTGC-dn & & & & \\
\hline \multirow[t]{2}{*}{ INRA124 } & GATCTTTGCAACTGGTTTG-up & 2 & $130-132$ & Y & Vaiman et al. (1994) \\
\hline & AGGACACAGGTCTGAGAATG-dn & & & & \\
\hline \multirow[t]{2}{*}{ INRA126 } & GTTGTTGCCTCTGCAGAGTAGG-up & 5 & $179-187$ & Y & Vaiman et al. (1994) \\
\hline & GACACTCTTTCTATTTTCAAGG-dn & & & & \\
\hline \multirow[t]{2}{*}{ INRA189 } & TTTTGTTTCCCGTGCTGAG-up & 2 & $152-160$ & MSY & Kappes et al. (1997) \\
\hline & GAACCTCGTCTCCTTGTAGCC-dn & & & & \\
\hline
\end{tabular}

${ }^{1}$ No. alleles and size range found in the 10 cattle families tested in this study.

${ }^{2}$ Following Liu \& Ponce de León (2007): PAR and MSY mean the pseudoautosomal and male-specific regions of BTAY respectively.

size, on loci INRA124 and INRA126, were sequenced from two individuals of each sex (including a female zebu in INRA124). For INRA124, we found one polymorphism with respect to the published sequence (Genbank accession no. X71546) (Appendix S1). For INRA126, three polymorphisms were found with respect to the published sequence (Genbank accession no. X71553) (Appendix S1). Altogether these results allowed us to rule out non-specific female amplification.
Liu et al. (2003) suggested three explanations as to why a Y-specific marker amplifies the same product from both male and female DNA: (i) the common origin of sexual chromosomes, with $\mathrm{X}$ - and $\mathrm{Y}$-specific regions still sharing homologous sequences across the genome; (ii) the existence of multiple copies of a given BTAY-specific marker along the chromosome; and (iii) non-specific PCR amplification of female DNA samples. If amplification products of BTAY microsatellites on female DNA differ in size to those obtained 


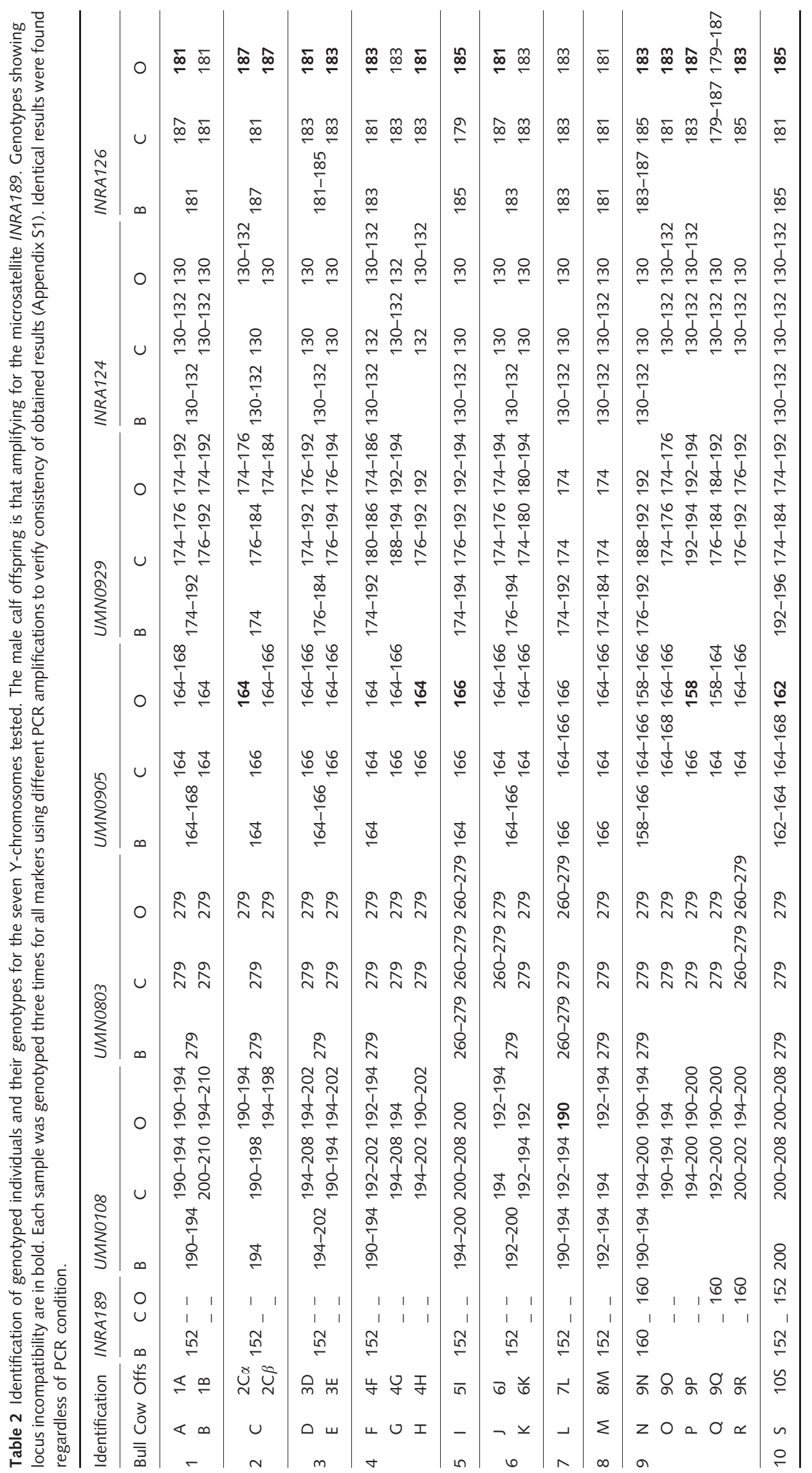


from male DNA, the Y-specificity of a microsatellite should be accepted. Here, we report that both markers do not meet with this 'rule of thumb' and phylogenetic studies in cattle should therefore be questioned.

This is the first time in which amplification of the microsatellite INRA124 on female DNA is reported (Fig. S1). Moreover, even though this marker has previously only been found to be polymorphic between B. taurus and B. indicus (Hanotte et al. 1997, 2000; Edwards et al. 2007; Li et al. 2007), we have also found polymorphism within both B. taurus and B. indicus. This was checked by genotyping 200 taurine male samples belonging to 37 European cattle breeds, four Brahman, two Brangus and four Indian Zebu sire samples (Table S1). Three different alleles (130, 132 and $134 \mathrm{bp}$ ) were found in the taurine samples and other three (126, 128 and 132) on the zebu males.

INRA124 has been frequently used in studies assessing admixture between B. taurus and B. indicus (Hanotte et al. 2000; Edwards et al. 2007; Li et al. 2007). As this marker undoubtedly amplifies the same PCR product on female taurine and zebu DNA, the occurrence of recombination events cannot be rejected. Therefore, the studies assessing male-mediated introgression events carried out on the basis of this marker alone should be interpreted with caution.

Some doubts on the Y-specificity of the marker INRA126 already existed. PCR products of the same size from both sexes have been reported on cattle (Liu et al. 2003), yaks (Edwards et al. 2000) and saola (Nguyen et al. 2005). This could indicate that, across bovids, the X-chromosome has retained a homologous sequence to the Y-chromosomal segment containing the INRA126 marker (Edwards et al. 2000) or that the location of the locus INRA126 is on the PAR-BTAY (Li et al. 2007). Here, we show that INRA126 amplifies from female DNA but also that this locus has a large variability within family. The large number of paternal incompatibilities that have accumulated on locus INRA126 (see Table 2) cannot be easily explained, even though unexpectedly high mutation rates together with chromosomal recombination could be the basis of the large variability assessed on this locus (Li et al. 2007). Whatever the explanation might be, the use of the locus INRA126 to characterize male evolutionary histories is questionable and not recommended.

Recently, Anderung et al. (2007) indicated the occurrence of hybridization between indicine and taurine cattle in Africa, and the presence of indicine $\mathrm{X}$ chromosomal recombinant forms. From our results, recombination events involving loci INRA124 and INRA126 cannot be rejected, and therefore use of these markers may distort actual indicine male-mediated ancestries.

Based on our findings, it is recommended that the INRA124 and INRA126 markers should not be used in studies to characterize male-mediated genetic events. Assessment of paternal genetic legacies would require thorough examination of BTAY-specific marker amplifica- tion patterns and segregation on female DNA. Previous cattle population studies using these markers alone should be interpreted with caution. New analyses using Y-specific markers are necessary to gain a better understanding of the different levels of admixture in breeds from different geographic areas and the ages of the admixtures (Anderung et al. 2007).

\section{Acknowledgements}

This study was partially funded by MEC-FEDER: CGL200503761/BOS and USDA-Hatch project MIN-16-019. L. Pérez-Pardal is funded by BES-2006-13545. We acknowledge Ligia Mercedes Jimenez Robayo, Maria Raquel Carvalho and Catarina Ginja for their help in sampling.

\section{References}

Anderung C., Hellborg L., Seddon J., Hanotte O. \& Götherstöm A. (2007) Investigation of X- and Y-specific single nucleotide polymorphisms in taurine (Bos taurus) and indicine (Bos indicus) cattle. Animal Genetics 38, 595-600.

Edwards C.J., Gaillard C., Bradley D.G. \& MacHugh D.E. (2000) Y-specific microsatellite polymorphism in a range of bovid species. Animal Genetics 31, 127-30.

Edwards C.J., Baird J.F. \& MacHugh D.E. (2007) Taurine and zebu admixture in Near Eastern cattle: a comparison of mitochondrial, autosomal and Y-chromosomal data. Animal Genetics $38,520-4$.

Giovambattista G., Ripoli M.V., De Luca J.C., Mirol P.M., Lirón J.P. \& Dulout F.N. (2000) Male-mediated introgression of Bos indicus genes into Argentine and Bolivian Creole cattle breeds. Animal Genetics 31, 302-5.

Hanotte O., Okomo M., Verjee Y., Rege E. \& Teale A. (1997) A polymorphic Y chromosomal microsatellite locus in cattle. Animal Genetics 28, 308-22.

Hanotte O., Tawah C.L., Bradley D.G., Okomo M., Verjee Y., Ochieng J. \& Rege J.E. (2000) Geographic distribution and frequency of a taurine Bos taurine and an indicine Bos indicus Y specific allele amongst sub-Saharan African cattle breeds. Molecular Ecology 9, 387-96.

Kappes S.M., Keele J.W., Stone R.T., McGraw R.A., Sonstegard T.S., Smith T.P., Lopez-Corrales N.L. \& Beattie C.W. (1997) A secondgeneration linkage map of the bovine genome. Genome Research 7, 235-49.

Li M.H., Zerabruk M., Vangen O., Olsaker I. \& Kantanen J. (2007) Reduced genetic structure of north Ethiopian cattle revealed by Y-chromosome analysis. Heredity 98, 214-8.

Liu W.-S. \& Ponce de León F.A. (2007) Mapping of the bovine Y chromosome. Electronic Journal of Biology 3, 5-12.

Liu W.-S., Beattie C.W. \& Ponce de León F.A. (2003) Bovine $\mathrm{Y}$ chromosome microsatellite polymorphism. Cytogenetic and Genome Research 10, 53-8.

MacHugh D.E. \& Bradley D.G. (2001) Livestock genetic origins: goats buck the trend. Proceedings of the National Academy of Sciences of the United States of America 98, 5382-4.

Nguyen T.T., Ménétrey F., Genini S., Nguyen V.L., Vögeli P., Nguyen B.X. \& Stranzinger G. (2005) Application of bovine 
microsatellite markers on Saola (Pseudoryx nghetinhensis). Journal of Animal Breeding and Genetics 122, 195-8.

Vaiman D., Imam-Ghali M., Moazami-Goudarzi K., Guerin G., Grohs C., Leveziel H. \& Saidi-Mehtar N. (1994) Conservation of a syntenic group of microsatellite loci between cattle and sheep. Mammalian Genome 5, 310-4.

\section{Supporting information}

Additional supporting information may be found in the online version of this article.

Figure S1 Genmapper image of INRA124 amplification (green lines due to VIC labelling of PCR products). Bands of different size form the GenScan 500-LIZ standard (orange).
Table S1 Number of genotyped individuals $(N)$ and allele frequency found on locus INRA124 in 37 bovine cattle breeds and some Zebu cattle samples.

Appendix S1 PCR conditions and DNA sequences of the markers used.

Please note: Wiley-Blackwell is not responsible for the content or functionality of any supporting information supplied by the authors. 